\title{
PEMANFAATANANALISIS BIAYA DAN MANFAAT DALAM PERHITUNGAN KELAYAKAN INVESTASI TEKNOLOGI INFORMASI
}

\author{
Heni Sulistiani ${ }^{1}$, Miswanto², Debby Alita ${ }^{3}$, Prita Dellia $^{4}$ \\ 1,2,3 Universitas Teknokrat Indonesia \\ Lampung, Indonesia \\ henisulistiani@teknokrat.ac.id \\ ${ }^{4}$ Universitas Trunojoyo Madura \\ Madura, Indonesia \\ prita.dellia@trunojoyo.ac.id
}

\begin{abstract}
Abstrak
CV Laut Selatan Jaya merupakan perusahaan yang bergerak di bidang pendistribusian dalam penjualan kosmetik di Bandar Lampung. CV Laut Selatan Jaya telah mengembangkan sebuah sistem untuk mengelola transaksi penjualan. Dalam pengembangan sistem tersebut, CV Laut Selatan Jaya mengeluarkan biaya yang tidak sedikit. Perusahaan perlu melakukan pengukuran investasi teknologi informasi agar sistem penjualan yang telah dikembangkan sesuai dengan kebutuhan perusahaan dan sejalan dengan visi misi perusahaan. Pengukuran ini juga diperlukan agar perusahaan tidak mengalami kegagalan dalam menginvestasikan dananya dalam pengembangan teknologi informasi. Dalam penelitian ini akan dilakukan analisis perhitungan biaya dan manfaat yang dirasakan oleh CV Laut Selatan Jaya. Berdasarkan hasil identifikasi dan perhitungan biaya yang dikeluarkan CV Laut Selatan Jaya untuk mengembangkan sistem penjualan sebesar Rp. 164.950.000, sedangkan manfaat yang dirasakan oleh perusahaan sebesar Rp. 182.029.000.
\end{abstract}

\section{Kata Kunci: Cost and Benefit, Investasi TI, Pengukuran}

\begin{abstract}
CV Laut Selatan Jaya is a company engaged in the distribution of cosmetics sales in Bandar Lampung. CV Laut Selatan Jaya has developed a system for managing sales transactions. In developing the system, CV Laut Selatan Jaya spent quite a lot of money. Companies need to measure information technology investments so that the sales system that has been developed is in accordance with the company's needs and in line with the company's vision and mission. This measurement is also needed so that companies do not experience failure in investing their funds in the development of information technology. In this study an analysis of the calculation of costs and benefits felt by CV Laut Selatan Jaya. Based on the identification and calculation of costs incurred by CV Laut Selatan Jaya to develop a sales system of Rp. 164,950,000 while the benefits felt by the company of Rp. 182,029,000.
\end{abstract}

Keywords: Cost and Benefit, IT Investment, Measurement 


\section{PENDAHULUAN}

Banyak perusahaan yang semakin memikirkan pentingnya kunci sukses dalam memenangkan persaingan dunia bisnis sangat bergantung pada kemampuan perusahaan untuk mendapatkan informasi yang berguna secara cepat dan tepat yang bertumpu pada nominal investasi (Miswanto et al , 2020). Ada perusahaan yang benar-benar memilih untuk menginvestasikan anggaran dananya untuk mengembangkan teknologi informasi yang setiap tahunnya terus mengalami perkembangan di dunia teknologi dan kebutuhan data (Sulistiani \& Delia, 2016). Penggunaan teknologi oleh perusahaan harus berbanding lurus dengan skala perusahaan, semakin besar perusahaan maka semakin besar investasi yang dibutuhkan (Sudrajat \& Rudianto, 2019). Agar perusahaan tidak mengalami kegagalan dalam menginvestasikan dananya untuk pengembangan teknologi informasi, maka diperlukan strategi untuk melakukan pengukuran investasi.

Investasi teknologi informasi dapat diukur melalui penilaian apakah teknologi informasi benar-benar mampu membantu kegiatan bisnis perusahaan ataukah tidak, apakah penggunaan teknologi informasi sudah efektif dan efisien (Mawlan \& Petrus, 2015). Pengukuran kelayakan investasi Sistem Informasi (SI)/ Teknologi Informasi (TI) bertujuan untuk mengetahui apakah suatu proyek dalam pengembangan SI/TI mampu memberikan manfaat bagi organisasi (manfaat yang bersifat tangible maupun intangible) dengan biaya yang sudah dikeluarkan oleh organisasi (Yulia, 2005). Terdapat beberapa metode yang dapat digunakan untuk pengukuran kelayakan investasi teknologi informasi, diantaranta cost and benefit analysis (Miswanto et al, 2020) (Sulistiani \& Delia, 2016) (Mawlan \& Petrus, 2015) (Sholiq et al, 2013), Information Economics (Sudarajat \& Rudianto, 2019) (Yulia, 2005) (Kristanto, 2018) (Novianti \& Susilawati, 2018) (Orianto \& Tanaamah, 2016) dan Logika Fuzzy (Hartati \& Widhiarso, 2010) (Martini, 2008).

Dalam penelitian ini akan diusulkan untuk melakukan perhitungan investasi teknologi informasi dengan menggunakan analisis biaya dan manfaat (cost and benefit analysis) di CV Laut Selatan Jaya. Dikarenakan metode ini merupakan metode yang melakukan perhitungan dari sisi efisiensi program atau sistem yang telah lama berjalan (Rahmiyati et al, 2018).

\section{METODE PENELITIAN}

Dalam melakukan penelitian, data yang dikumpulkan akan digunakan untuk memecahkan masalah yang ada sehingga data tersebut harus benar-benar dapat dipercaya dan akurat. Dalam suatu penelitian ilmiah, metode pengumpulan data dimaksudkan untuk memperoleh bahan-bahan yang relevan, akurat, dan terpercaya. Metode pengumpulan data yang dilakukan dalam penelitian ini adalah:

\section{Observasi}

Melakukan pengamatan terhadap data yang diteliti, melakukan interview dengan pihak-pihak yang berkaitan dengan pembuatan program untuk mengetahui Sistem Penjualan untuk menganalisis CBA pada CV Laut Selatan Jaya.

2. Wawancara 
Pengumpulan data dengan cara mengajukan pertanyaan secara langsung kepada pihak keuangan CV Laut Selatan Jaya.

3. Dokumentasi

Pengumpulan data dengan teknik dokumentasi dilakukan dengan mengumpulkan dokumen-dokumen yang berkaitan dengan investasi pengembangan sistem penjualan, seperti laporan keuangan dalam pengembangan sistem, hasil wawancara dan lain sebagainya.

\section{Studi Literatur}

Studi literatur yang digunakan yaitu buku-buku, jurnal, prosiding yang menyajikan informasi tentang CBA, HTML, WEB Sistem dan MYSQL.

Metode CBA (Cost and Benefit Analysis) yang digunakan dalam penelitian ini merupakan analisis yang dilakukan dengan membandingkan antara biaya (cost) yang sudah dikeluarkan untuk mengembangkan sistem penjualan dengan manfaat (benefit) atau keuntungan yang diperoleh CV Laut Selatan Jaya. Unsur biaya merupakan komponen nilai-nilai yang dikeluarkan untuk mengembangkan sistem penjualan. Sedangkan unsur manfaat merupakan nilai positif dan negatif yang dirasakan oleh perusahaan dengan diterapkannya sistem penjualan. Komponen biaya dan manfaat yang digunakan dalam penelitian ini mencakup tangible dan intangible.

\section{HASIL PENELITIAN DAN PEMBAHASAN}

Sebelum dilakukan pengukuran terhadap nilai biaya dan manfaat dalam pengembangan sistem penjualan di $\mathrm{CV}$ Laut Selatan jaya, perlu dilakukan identifikasi terhadap biaya-biaya yang dikeluarkan dalam pengembangan sistem dan manfaat yang dirasakan oleh perusahaan setelah penerapan sistem penjualan. Identifikasi unsur biaya dan mafaat akan dijelaskan sebagai berikut:

\section{Identifikasi Biaya}

Komponen biaya yang digunakan dalam penelitian ini adalah sebagai berikut:

a. Procurement Cost

Procurement Cost merupakan total semua biaya pengadaan perangkat keras yang di investasikan untuk menunjang kebutuhan bisnis. Berikut merupakan procurement yang dikeluarkan oleh CV Laut Selatan Jaya dari awal pengembangan sistem penjualan. Biaya procurement ini dikeluarkan pada tahun-tahun pertama penggunaan sistem penjualan. Daftar biaya ini dapat dilihat pada Tabel 1.

Tabel 1. Daftar Biaya Procurement

\begin{tabular}{lc}
\hline \multicolumn{1}{c}{ Nama Kebutuhan } & Biaya (Rp) \\
\hline Komputer & 4.700 .000 \\
Jaringan Speedy / Wifi & 550.000 \\
Printer Canon PIXMA & 1.600 .000 \\
287 2 Buah @ Rp. & \\
800.000 & \\
AC 2 Buah @ Rp. & 6.000 .000 \\
3.000.000 & \\
Kipas Angin 2 Buah @ & 500.000 \\
Rp. 250.000 & \\
TV LED Samsung 32 in & 3.800 .000 \\
43K5002 & \\
Proyektor Epson EB- & 5.700 .000 \\
X450 & \\
\hline
\end{tabular}

b. Start up Cost

Start up cost merupakan biaya yang harus dikeluarkan untuk mendukung kebutuhan operasional. Sama seperti 
procurement, start up cost biasanya dikeluarkan pada tahun-tahun pertama pengembangan sistem penjualan. Daftar start up cost dapat dilihat pada Tabel 2.

Tabel 2. Daftar Start Up Cost

\begin{tabular}{lc}
\hline \multicolumn{1}{c}{ Nama Kebutuhan } & Biaya (Rp) \\
\hline Biaya Progammer 2 & 8.200 .000 \\
Orang @ Rp 4.100.000 & \\
Pembelian Sistem & 4.500 .000 \\
Penjualan & \\
Biaya Instalasi Jaringan & 100.000 \\
Biaya Perlengkapan & 500.000 \\
\hline
\end{tabular}

c. Project Cost

Project Cost atau biaya proyek adalah total biaya yang harus dikeluarkan pada saat menerima proyek. Biaya ini terdiri dari biaya kebutuhan - kebutuhan dari pengembangan sebuah proyek. Biaya ini merupakan modal yang digunakan untuk

mendukung

proses keberlangsungan sebuah proyek. Daftar biaya proyek dapat dilihat pada Tabel 3.

Tabel 3. Daftar Biaya Proyek

\begin{tabular}{lc}
\hline \multicolumn{1}{c}{ Nama Kebutuhan } & Biaya (Rp) \\
\hline Hosting & 300.000 \\
Biaya Pelatihan & 500.000 \\
Penerapan Program & 500.000 \\
Akomodasi Proyek & \\
\hline
\end{tabular}

d. Ongoing Cost

Ongoing Cost merupakan biaya-biaya yang harus dikeluarkan pada saat proyek telah dilaksanakan. Biaya ini terdiri dari biaya perawatan dan perbaikan sistem penjualan yang digunakan oleh CV Laut Selatan Jaya. Daftar ongoing cost dapat dilihat pada Tabel 4.

Tabel 4. Daftar Ongoing Cost

\begin{tabular}{|c|c|c|c|c|}
\hline Nama Kebutuhan & Th 0 (Rp) & Th 1 (Rp) & Th 2 (Rp) & Th 3 (Rp) \\
\hline $\begin{array}{l}\text { Gaji Karyawan } 4 \text { Orang } \\
@ \text { Rp. } 2.100 .000\end{array}$ & 0 & 100.800 .000 & 103.824 .000 & 106.938 .720 \\
\hline $\begin{array}{l}\text { Biaya perawatan } \\
\text { perangkat lunak }\end{array}$ & 0 & 3.000 .000 & 3.090 .000 & 3.182 .700 \\
\hline $\begin{array}{l}\text { Biaya perawatan } \\
\text { perangkat keras }\end{array}$ & 0 & 5.000 .000 & 5.150 .000 & 5.304 .500 \\
\hline $\begin{array}{l}\text { Pembelian Perlengkapan } \\
\text { dan Fasilitas }\end{array}$ & 0 & 8.500 .000 & 8.755 .000 & 9.017 .650 \\
\hline Biaya ATK & 0 & 3.000 .000 & 3.090 .000 & 3.182 .700 \\
\hline Listrik & 0 & 7.200 .000 & 7.416 .000 & 7.638 .480 \\
\hline
\end{tabular}

Berdasarkan data unsur biaya pada tahun ke 0 dan dilakukan analisis selama 3 tahun, tiap tahunnya mengalami kenaikan biaya nilai tukar rupiah terhadap dollar ataupun kenaikan laju inflasi rupiah. Seluruh biaya diasumsikan mengalami kenaikan sebesar 3\% yang mengacu pada kenaikan insflasi pada bulan Januari
2016 hingga Januari 2019 yang berkisar $3 \%$ per tahun.

\section{Identifikasi Manfaat}

Identifikasi manfaat bertujuan untuk mengetahui manfaat yang didapat dari implementasi sistem penjualan pada $\mathrm{CV}$ Laut Selatan Jaya. Manfaat dibedakan menjadi manfaat berwujud (tangible) dan yang tidak berwujud (intangible). 
a. Manfaat Berwujud (Tangible Benefit)

Manfaat Berwujud dari investasi Sistem Penjualan diperoleh melalui penghematan biaya akibat adanya investasi tersebut. Analisis manfaat berwujud dilakukan dengan empat metode pendekatan, yaitu cost displacement, cost avoidance, decision analysis dan impact analysis.

(1) Cost Displacement
Cost Displacement merupakan sebuah metode pendekatan untuk mengidentifikasi manfaat berwujud yang diperoleh CV Laut Selatan Jaya untuk dapat mereduksi biaya yang dikeluarkan perusahaan akibat investasi sistem penjualan. Sehingga dapat dijadikan sarana untuk meningkatkan kinerja yang efisien. Manfaat yang muncul dengan pendekatan cost displacement dapat dilihat pada Tabel 5.

Tabel 5. Manfaat Cost Displacement

\begin{tabular}{|c|c|c|}
\hline Manfaat & Sistem Lama & Sistem Baru \\
\hline $\begin{array}{l}\text { Pengurangan } \\
\text { Biaya Buku } \\
\text { Besar }\end{array}$ & $\begin{array}{l}\text { Untuk setiap transaksi } \\
\text { penjualan masih dicatat } \\
\text { didalam buku besar }\end{array}$ & $\begin{array}{l}\text { Untuk setiap transaksi penjualan } \\
\text { disimpan didalam database dan dapat } \\
\text { dicetak, sehingga biaya pembelian buku } \\
\text { besar dapat dikurangi. }\end{array}$ \\
\hline $\begin{array}{l}\text { Pengurangan } \\
\text { Kertas Nota }\end{array}$ & $\begin{array}{l}\text { Untuk setiap transaksi } \\
\text { masih menggunakan nota } \\
\text { yang masih ditulis tangan }\end{array}$ & $\begin{array}{l}\text { Untuk setiap transaksi bukti penjualan } \\
\text { dapat dicetak menggunakan aplikasi } \\
\text { faktur penjualan, sehingga biaya } \\
\text { pembelian kertas nota dapat dikurangi }\end{array}$ \\
\hline $\begin{array}{l}\text { Pengurangan } \\
\text { Biaya Telepon/ } \\
\text { Pulsa }\end{array}$ & 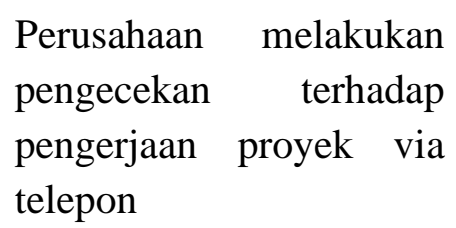 & $\begin{array}{l}\text { Perusahaan melakukan pengecekan } \\
\text { langsung pada aplikasi faktur pejualan }\end{array}$ \\
\hline $\begin{array}{l}\text { Pengurangan } \\
\text { Biaya Bolpoin }\end{array}$ & $\begin{array}{l}\text { Untuk setiap pencatatan } \\
\text { dibuku besar dan nota } \\
\text { masih menggunakan alat } \\
\text { tulis bolpoin }\end{array}$ & $\begin{array}{l}\text { Pada sistem baru sudah menggunakan } \\
\text { aplikasi faktur penjualan, sehingga biaya } \\
\text { untuk pembelian bolpoin dapat dikurangi }\end{array}$ \\
\hline $\begin{array}{l}\text { lu dilakukan ana } \\
\text { langan yang dil } \\
\text { ikut: } \\
\text { Pengurangan Bia } \\
\text { Berikut estimas } \\
\text { xu besar dalam sc }\end{array}$ & $\begin{array}{l}\text { si semua manfaat } \\
\text { oendekatan cost } \\
\text { at mengetahui nilai } \\
\text { keuangan. Analisis } \\
\text { kan adalah sebagai }\end{array}$ & $\begin{array}{l}\text { Penghematan Biaya }=\text { jumlah buku } \\
\text { besar selama satu tahun } * \text { biaya buku } \\
\text { besar } \\
\text { Dengan menggunakan persamaan di } \\
\text { atas, besar manfaat dari pengurangan biaya } \\
\text { buku besar berdasarkan data yang } \\
\text { diperoleh adalah dibutuhkan } 10 \text { buku besar } \\
\text { selama satu tahun. Harga untuk } 1 \text { buku } \\
\text { besar adalah Rp. } 40.000 \text { Jadi biaya } \\
\text { penghematan buku besar dalam satu tahun } \\
\text { sebesar: } 10 * \text { Rp. } 40.000=\text { Rp. } 400.000 .\end{array}$ \\
\hline
\end{tabular}


2) Pengurangan Biaya Kertas Nota

Berikut estimasi pengurangan biaya kertas dalam satu tahun:

Penghematan Biaya $=$ jumlah biaya kertas nota selama satu tahun * biaya kertas nota

Dengan menggunakan persamaan di atas, besar manfaat dari pengurangan biaya kertas nota berdasarkan data yang diperoleh adalah dibutuhkan 50 kertas nota selama satu tahun. Harga untuk 1 kertas nota adalah Rp. 7.000 Jadi biaya penghematan kertas nota dalam satu tahun sebesar: $50 *$ Rp. $7.000=$ Rp. 350.000 .

3) Pengurangan Biaya Telepon/ pulsa

Berikut estimasi pengurangan biaya telepon/pulsa dalam satu tahun:

Penghematan Biaya $=$ jumlah pulsa selama satu tahun * biaya pulsa

Dengan menggunakan persamaan di atas, besar manfaat dari pengurangan biaya telepon/pulsa berdasarkan data yang diperoleh adalah dibutuhkan pulsa Rp. 800.000 untuk dua karyawan selama satu tahun. Jadi biaya penghematan pulsa dalam satu tahun sebesar: $2 *$ Rp. 800.000 $=$ Rp. 1.600.000.

4) Pengurangan Biaya Bolpoin

Berikut estimasi pengurangan biaya bolpoin dalam satu tahun:

Penghematan Biaya = jumlah biaya bolpoin selama satu tahun * biaya bolpoin

Dengan menggunakan persamaan di atas, besar manfaat dari pengurangan biaya bolpoin berdasarkan data yang diperoleh adalah dibutuhkan 5 kotak bolpoin selama satu tahun. Harga untuk 1 kotak bolpoin adalah Rp.35.000 jadi biaya penghematan biaya bolpoin dalam satu tahun sebesar: 5 * Rp. $35.000=$ Rp. 175.000 .

Dengan penerapan sistem penjualan dapat menghemat pengeluaran biaya karena adanya pengurangan dari biayabiaya yang telah disebutkan di atas dalam satu tahun adalah sebesar Rp. 2.525.000. Rincian pengurangan biaya dapat dilihat pada Tabel 6.

Tabel 6. Rincian Pengurangan Biaya

\begin{tabular}{lc}
\hline \multicolumn{1}{c}{ Nama } & \multicolumn{1}{c}{$\begin{array}{c}\text { Total } \\
(\mathbf{R p})\end{array}$} \\
\hline $\begin{array}{l}\text { Pengurangan Biaya Buku } \\
\text { Besar }\end{array}$ & 400.000 \\
Pengurangan Biaya Kertas & \\
Nota & 350.000 \\
Pengurangan Biaya & \\
Telepon/ Pulsa & 1.600 .000 \\
Pengurangan Biaya & 175.0 \\
Bolpoin & \\
\hline
\end{tabular}

(2)Cost Avoidance

Cost Avoidance merupakan sebuah metode pendekatan untuk mengidentifikasi manfaat berwujud yang diperoleh. Untuk dapat menghindari biaya yang harus dikeluarkan yang disebabkan adanya investasi sistem penjualan. Manfaat yang muncul dari pendekatan cost avoidance dapat dilihat pada Tabel 7.

Tabel 7. Manfaat Cost Avoidance

\begin{tabular}{lll}
\hline \multicolumn{1}{c}{ Manfaat } & Sistem Lama & Sistem Baru \\
\hline Penghilangan & Perusahaan & Pengecekan \\
biaya & mengirimkan & proyek dapat \\
karyawan & $2 \quad$ orang & dilakukan \\
untuk & karyawan & dengan \\
kegiatan & untuk & melihat di \\
pengecekan & pengecekan & Sistem \\
data & data & Penjualan \\
penjualan & penjualan & \\
\hline
\end{tabular}


Jumlah karyawan yang dikirimkan untuk pengecekan data penjualan yaitu dua orang. Besaran biaya pengeluaran dinas dapat dilihat pada Tabel 8.

Tabel 8 Rincian Biaya Pengeluaran Dinas

\begin{tabular}{|l|l|}
\hline \multicolumn{1}{|c|}{ Biaya Pengeluaran } & \multicolumn{1}{c|}{$\begin{array}{c}\text { Jumlah } \\
\text { (Rp) }\end{array}$} \\
\hline $\begin{array}{l}\text { Transportasi pulang - pergi (2 } \\
\text { orang) }\end{array}$ & 500.000 \\
\hline $\begin{array}{l}\text { Konsumsi (uang makan untuk } \\
\text { 2 orang) }\end{array}$ & 200.000 \\
\hline Gaji luar dinas (2 orang) & 300.000 \\
\hline
\end{tabular}

Penghematan biaya karyawan dalam pengecekan proyek terdapat dua kali kunjungan, sehingga didapatkan dengan persamaan:

Penghilangan Biaya $=$ jumlah kunjungan * Biaya sekali kunjungan

Dengan menggunakan persamaan di atas, besar manfaat yang diperoleh dari penghilangan biaya karyawan untuk melakukan pengecekan proyek adalah:

Penghilangan Biaya $=\mathbf{2} * \mathbf{R p}$. 1.000.000 = Rp. 2.000.000

Jadi, dengan adanya sistem penjualan PT XYZ mampu menghemat biaya perjalanan dinas dalam satu tahun sebesar

Rp. 2.000.000.

\section{(3)Decision Analysis}

Decision Analysis merupakan sebuah metode pendekatan untuk mengidentifikasi manfaat berwujud yang diperoleh untuk memperbaiki kualitas keputusan yang diambil dengan adanya sistem penjualan. Estimasi manfaat dari pendekaran decision analysis dapat dilihat pada tabel 9 .
Tabel 9. Manfaat Decision Analysis

\begin{tabular}{lll}
\hline Manfaat & $\begin{array}{c}\text { Sistem } \\
\text { Lama }\end{array}$ & Sistem Baru \\
\hline Pembelian & Setiap & Untuk \\
biaya & transaksi & mempermudah \\
proyek & masih & dalam \\
& ditulis & melakukan \\
& dibuku & transaksi \\
& besar & \\
\hline
\end{tabular}

Proses pembelian proyek yang dilakukan oleh PT XYZ terdapat 100\% pelunasan pembayaran pembelian proyek, dimana pembayaran pembelian proyek sebesar

\section{Rp. 13.300.000.}

\section{(4)Impact Analysis}

Impact analysis merupakan sebuah metode pendekatan untuk mengidentifikasi manfaat berwujud yang diperoleh karena adanya investasi Sistem Penjualan. Pendekatan ini biasanya terkait penghematan waktu yang berdampak pada penghematan biaya. Estimasi manfaat impact analysis dapat dilihat pada Tabel 10.

Tabel 10. Manfaat Impact Analysis

\begin{tabular}{|c|c|c|}
\hline Manfaat & $\begin{array}{c}\text { Sistem } \\
\text { Lama }\end{array}$ & $\begin{array}{c}\text { Sistem } \\
\text { Baru }\end{array}$ \\
\hline $\begin{array}{l}\text { Percepatan } \\
\text { waktu dalam } \\
\text { pencarian } \\
\text { data }\end{array}$ & $\begin{array}{l}\text { Data masih } \\
\text { ditulis di } \\
\text { buku besar }\end{array}$ & $\begin{array}{l}\text { Data berada } \\
\text { didalam } \\
\text { Sistem }\end{array}$ \\
\hline $\begin{array}{l}\text { Penghematan } \\
\text { waktu dalam } \\
\text { pengecekan } \\
\text { data } \\
\text { penjualan }\end{array}$ & $\begin{array}{l}\text { Karyawan } \\
\text { berkunjung } \\
\text { untuk } \\
\text { mengecek } \\
\text { data } \\
\text { penjualan }\end{array}$ & $\begin{array}{l}\text { karyawan } \\
\text { dapat } \\
\text { melakukan } \\
\text { pengecekan } \\
\text { melalui } \\
\text { sistem }\end{array}$ \\
\hline
\end{tabular}

Setelah mengidentifikasi semua manfaat berwujud dari pendekatan impact analysis, maka untuk mengetahui nilai 
dari manfaat perlu dilakukan analisis keuangan sebagai berikut:

1) Percepatan waktu dalam pencarian dokumen

Berikut estimasi percepatan waktu yang dihasilkan oleh sistem penjualan dalam proses pencarian dokumen:

Manfaat percepatan waktu dalam pencarian data = biaya insentif karyawan untuk mencari dokumen tiap pencarian data * percepatan waktu pencarian data

Dengan menggunakan persamaan di atas, besar manfaat dari percepatan waktu dalam pencarian data adalah:

a) Waktu yang dibutuhkan untuk mencari data dalam 1 hari $=5$ menit

b) Waktu yang dibutuhkan untuk mencari data dalam 1 bulan $=5$ menit $* 26$ hari kerja $=130$ menit

c) Waktu yang dibutuhkan untuk mencari data dalam 1 tahun $=130 *$ $12=1.560$ menit

d) Biaya insentif karyawan untuk tiap mencari data $=$ Rp. 1.500

Jadi, nilai manfaat dari percepatan waktu dalam pencarian data dalam satu tahun adalah sebesar $=$ Rp. 1.500

$* 1560=$ Rp. 2.340.000.

2) Penghematan waktu dalam pengecekan data penjualan

Berikut estimasi penghematan waktu dalam pengecekan proyek berdasarkan data yang diperoleh:
Penghematan waktu dalam pengecekan proyek $=$ Penghematan biaya dalam waktu satu bulan * satu tahun

a) Reduksi durasi telepon = waktu durasi telepon sebelum menggunakan Sistem Penjualan waktu durasi telepon setelah menggunakan Sistem Penjualan $=30$ menit -20 menit $=10$ menit

b) Biaya untuk 1 menit telepon sebesar Rp. 1.500

c) Biaya untuk satu kali kegiatan pengecekan $=10 *$ Rp. $1.500=\mathrm{Rp}$. 15.000

d) Rata - rata kegiatan pengecekan dalam satu bulan yaitu dua kali

e) Penghematan biaya dalam waktu satu bulan $=\mathrm{Rp} .15 .000 * 2=\mathrm{Rp}$. 30.000

Jadi, nilai manfaat dari penghematan waktu dalam pengecekan proyek dalam satu tahun adalah sebesar $=\mathbf{R p .} \mathbf{3 0 . 0 0 0} *$ 12

$=$ Rp. 360.000.

b. Manfaat Tidak Berwujud (Intangible Benefit)

Sedangkan manfaat tidak berwujud terdiri dari peningkatan motivasi karyawan, peningkatan moral kerja karyawan dan pelayanan yang lebih baik kepada pelanggan. Berdasarkan hasil wawancara dengan pihak CV Laut Selatan Jaya, manfaat tidak berwujud yang diperoleh dari implementasi sistem penjualan antara lain peningkatan motivasi karyawan atau anggota tim yang berdampak pada produktivitas karyawan, peningkatan moral kerja karyawan yang berdampak pada pengurangan kecurangan atau ketidak jujuran karyawan. Keuntungan tidak berwujud mempunyai sumbangsih yang cukup besar bagi perusahaan, sehingga manfaat tidak berwujud harus tetap diperhatikan walaupun sulit diukur dalam bentuk satuan 
nilai uang. Berikut adalah penjelasan dari manfaat tidak berwujud:

(1)Peningkatan produktivitas karyawan Adanya sistem penjualan memberikan kemudahan bagi para karyawan sehingga mereka merasa termotivasi dalam menyelesaikan tugas dan tanggung jawabnya. Dengan adanya peningkatan motivasi karyawan, produktivitas karyawan menjadi bertambah sehingga pekerjaan dapat diselesaikan lebih cepat. Peningkatan produktivitas karyawan ini dapat diukur dengan menggunakan penaksiran bersama pihak perusahaan dengan menetapkan persentase kemungkinan peningkatannya. Berikut adalah hasil penaksirannya:

a) Kemungkinan $50 \%$ karyawan produktivitasnya bertambah $20 \%$

b) Kemungkinan $30 \%$ karyawan produktivitasnya bertambah $50 \%$

c) Kemungkinan 20\% karyawan produktivitasnya bertambah $70 \%$

Selanjutnya dihitung perkiraan peningkatan produktivitas karyawan sebagai berikut:

Peningkatan Produktivitas

$=(50 \% \times 20 \%)+(30 \% \times 50 \%)+$ $(20 \% \times 70 \%)$

$$
=(10 \%+15 \%+14 \%)=39 \%
$$

Jika rata-rata gaji karyawan tiap tahun sebesar Rp. 100.800.000 maka dapat diperkirakan perusahaan akan mendapatkan keuntungan sebesar 39\% dari nilai gaji karyawan sebesar Rp. 39.312.000. Jika pada CV Laut Selatan Jaya memiliki 4 karyawan dalam pengelolaan proyek, maka jumlah penghematan dari adanya peningkatan produktivitas karyawan adalah:
Peningkatan produktivitas karyawan

= Rp. 39.312.000 * 4 karyawan

$=$ Rp. 157.248.000

(2)Peningkatan moral kerja karyawan

Adanya sistem penjualan dapat mengurangi terjadinya kecurangan atau ketidakjujuran karyawan dalam hal saling lempar tanggung jawab, sehingga dapat mengurangi kerugian akibat kecurangan karyawan. Dengan berkurangnya kecurangan karyawan, menandakan bahwa moral kerja karyawan meningkat. Peningkatan moral kerja ini dapat diukur dengan menggunakan penaksiran bersama pihak perusahaan dengan menetapkan persentase kemungkinan peningkatannya. Berikut adalah hasil penaksirannya:

a) Kemungkinan $40 \%$ karyawan moral kerja meningkat 20\%

b) Kemungkinan 20\% karyawan moral kerja meningkat $50 \%$

c) Kemungkinan $20 \%$ karyawan moral kerja meningkat $70 \%$

Selanjutnya dihitung perkiraan peningkatan moral kerja karyawan sebagai berikut:

Peningkatan moral kerja

$=(40 \% \times 20 \%)+(20 \% \times 50 \%)+$ $(20 \% \times 70 \%)$ $=(8 \%+10 \%+14 \%)=32 \%$

Jika rata-rata perkiraan kecurangan yang dilakukan karyawan, seperti saling lempar tanggung jawab, yang akan menyebabkan waktu pengerjaan proyek akan tertunda. Diperkirakan jumlah pembayaran proyek yang tertunda akibat kecurangan tersebut adalah sebesar Rp. 13.300.000. Maka dapat diperkirakan perusahaan akan 
mendapatkan keuntungan sebesar 32\% dari nilai penundaan pembayaran proyek sebesar Rp. 4.256.000.

\section{KESIMPULAN DAN SARAN}

Berdasarkan hasil perhitungan kelayakan investasi teknologi informasi menggunakan analisis biaya dan manfaat dapat disimpulkan sebagai berikut:

1. Dari hasil identifikasi dan perhitungan biaya diketahui bahwa CV Laut Selatan Jaya mengembangkan sistem penjualan menggunakan empat komponen yaitu procurement cost, start up cost, project related cost dan on going cost. Total biaya yang dikeluarkan untuk procurement cost sebesar $\mathrm{Rp}$. 22.850.000, untuk start up cost sebesar Rp. 13.300.000, untuk project related cost sebesar Rp. 1.300.000 dan untuk on going cost pada tahun pertama sebesar Rp. 127.500.000.

2. Dari hasil identifikasi dan perhitungan manfaat diketahui bahwa dengan adanya sistem penjualan di CV Laut Selatan Jaya mampu memberikan manfaat berupa tangible dan intangible. Total manfaat tangible yang diperoleh CV Laut Selatan Jaya adalah sebesar Rp. 20.525.000 dan manfaat intangible sebesar Rp. 161.504.000.

\section{UCAPAN TERIMA KASIH}

Penulis mengucapkan terima kasih kepada Direktorat Riset dan Pengabdian Masyarakat, Kemenristek/BRIN RI yang telah memberi dukungan terhadap seluruh kegiatan penelitian yang dilaksanakan pada tahun 2020.

\section{DAFTAR PUSTAKA}

Ayu Laili Rahmiyati, Asep Dian Abdillah, Susilowati dan Dinna Anggaraini. (2018). Cost Benefit Analysis (CBA) Program Pemberian Makanan Tambahan (PMT) Susu pada Karyawan di PT. Trisula Textile Industries Tbk Cimahi Tahun 2018. Jurnal Ekonomi Kesehatan Indonesia.

Budi Sudrajat, Rudianto. (2019). Analisis Kelayakan Investasi teknologi Informasi menggunakan Metode Information Economics. Jurnal Informatika dan Rekayasa Perangkat Lunak, Vol 1, No 2, September 2019.

Bagus Kristomoyo Kristanto. (2018). Studi Kelayakan Implementasi Sistem Informasi Klinik Mata Mojoagung Menggunakan Information Economics. Jurnal Dinamika Dotcom, Vol. 9, No. 2, Juli 2018.

Eva Novianti, Endang Ayu Susilawati. (2018). Analisis Investasi Teknologi Informasi pada Grand Hyatt Hotel Jakarta : Pendekatan IE. Seminar Nasional Teknik Elektro 2018.

Fandi Orianto, Andeka Tanaamah. (2016). Analisa Kelayakan Investasi Teknologi Informasi dengan Menggunakan Metode Information Economis (Studi Kasus: RSUD Tidar Magelang). Program Studi Sistem Informasi Fakultas Teknologi Informasi, Universitas Kristen Satya Wacana.

Heni Sulistiani, Prita Dellia. (2016). Evaluasi Kelayakan Investasi 
Teknologi Informasi Menggunakan Metode Cost Benefit Analysis. Konferensi Nasional Sistem Informasi 2016.

Miswanto, Heni Sulistiani, Damayanti. (2020). Penerapan Metode Cost and Benefit Analysis dalam Pengukuran Investasi Teknologi Informasi (Studi Kasus: CV Laut Selatan Jaya). Jurnal Tekno Kompak, Vol 14, No 1.

Sholiq, Arrizqy Nur Shabrina. (2013). Analisis Kelayakan Investasi Aplikasi Point of Sale pada Toko Grosir dan Ecer dengan Cost Benefit Analysis (Studi Kasus: Toko Nirwana Pamekasan). Seminar Nasional Sistem dan Teknologi Informasi (SNASTI).

Sri Hartati, Wijang Widhiarso. (2010). Evaluasi Kelayakan Nilai dan Resiko Bisnis Investasi Teknologi Informasi Menggunakan Metode Logika Fuzzy. Seminar Nasional Aplikasi Teknologi Informasi (SNATI).

Sri Martini. (2008). Model Investasi Fuzzy untuk Analisis Kelayakan Finansial Usaha Diversifikasi Industri Berbasis Tebu. Sekolah Pascasarjana Institut Pertanian Bogor.

Suwirno Mawlan, Johanes Petrus. (2015). Analisis Kelayakan Ekonomis TI Pemesanan Bahan Persediaan Fried Chicken Berbasis Web Menggunakan Metode Cost Benefit (Studi Kasus: PT XYZ). Seminar Nasional Ekonomi Manajemen dan Akuntansi (SNEMA) Fakultas Ekonomi Universitas Negeri Padang.
Yulia. (2005). Kajian Kelayakan Investasi Proyek Teknologi Informasi dengan Menggunakan Metode Information Economics. Jurusan Teknik Informatika, Fakultas Teknologi Industri-Universitas Kristen Petra. 